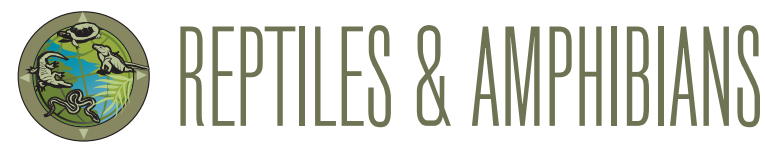

\title{
Predation on a Common Wolfsnake, Lycodon aulicus (Colubridae), by an Indian Roller, Coracias benghalensis (Coraciidae), in the Sathyamangalam Tiger Reserve, Tamil Nadu, India
}

\author{
Sreedharan Nair Vishnu and Chinnasamy Ramesh
}

Wildlife Institute of India, Chandrabani, Dehradun-248002, Uttarakhand, India (ramesh.czoo@gmail.com)

Photographs by the senior author.

$\mathrm{T}$ he Common Wolfsnake (Lycodon aucilus), which is widely distributed across southern Asia, is active at night and often forages among rocks and on walls and other rough surfaces in which holes and crevices are used as diurnal refugia (Whitaker and Captain 2004). Adults grow to a maximum length of about $92 \mathrm{~cm}$ (Vyas and Patel 1995).

The Indian Roller (Coracias benghalensis) ranges from western Asia across the entire Indian Subcontinent (BirdLife International 2016). Indian Rollers prey primarily on small insects, mostly on the ground and particularly during evening hours, but also will capture flying insects (Ali and Ripley 2001; Sivakumaran and Thiyagesan 2003; Asokan et al. 2009).

On the morning of 17 March 2019, while tracking radiotagged Indian Pythons (Python molurus) in the Mangalapatti Beat of the Sathyamangalam Tiger Reserve (STR) in Tamil $\mathrm{Nadu}$, India $\left(11.581687^{\circ} \mathrm{N}, 76.906151^{\circ} \mathrm{E}\right)$, we encountered an Indian Roller feeding on a snake. The STR is part of the Segur Plateau (elev. 209-1,950 m asl) at the confluence of the Western and Eastern Ghats.

At $1008 \mathrm{~h}$, the Indian Roller emerged from thorny roadside scrub comprised mostly of invasive Mesquite (Prosopis juliflora) and native Bush Plum (Caraissa spinarum), picked up its prey, and landed on the unpaved road (Fig. 1). The snake struggled, constricted the beak of the roller, and tried to

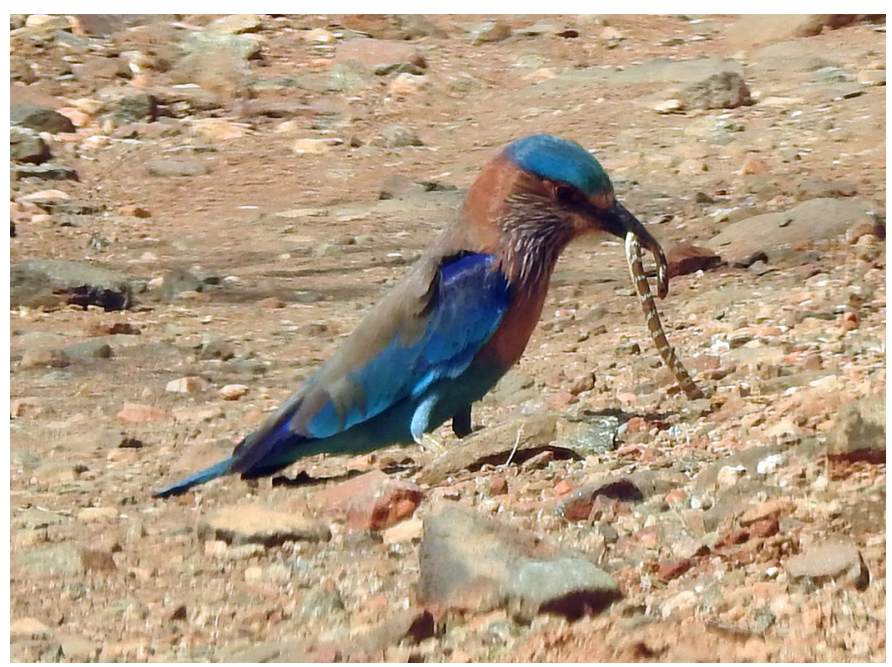

Fig. 1. An Indian Roller (Coracias benghalensis) had captured a Common Wolfsnake (Lycodon aucilus) before landing on the road.
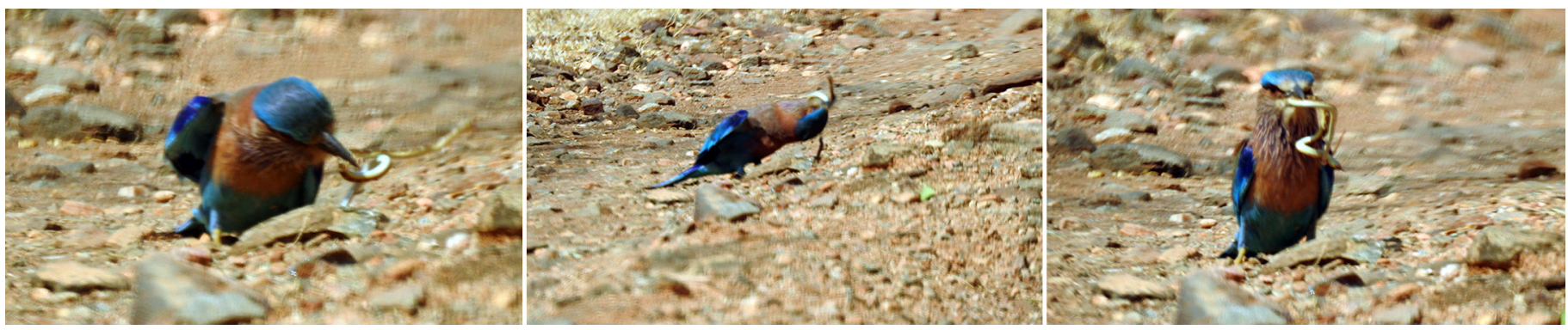

Fig. 2. A Common Wolfsnake (Lycodon aucilus) struggling to escape from an Indian Roller (Coracias benghalensis). 

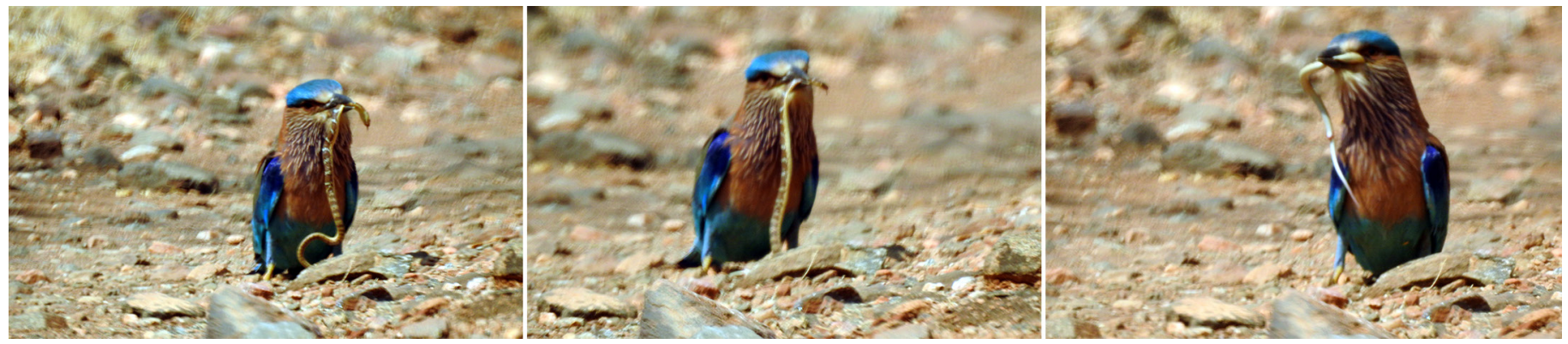

Fig. 3. When the Common Wolfsnake (Lycodon aucilus) ceased moving, the Indian Roller (Coracias benghalensis) swallowed it before flying away.

bite the bird (Fig. 2). The roller pecked the snake and jumped on it multiple times. Finally, as the snake's movements ceased, the roller swallowed it (Fig. 3) and flew away. This entire episode lasted just $7 \mathrm{~min}$. We identified the approximately $20-\mathrm{cm}$ long prey as a Common Wolfsnake by studying the photographs taken during the feeding event.

Biddulph (1937) reported an Indian Roller eating an unidentified snake and Soud et al. (2010) described a Common Wolfsnake taken by a White-throated Kingfisher (Halcyon smyrnensis) in a forested area on the Assam University campus. This, however, is the first record of an Indian Roller feeding on a Common Wolfsnake.

\section{Acknowledgements}

Research grant DST-SERB (EMR/2016/003963) by the Government of India provided funding for the fieldwork during which we made the observation described above. That research was approved by the Ministry of Environment, Forests and Climate Change, Government of India, and the Tamil Nadu Forest Department (No. WL5(A) /17699/2017; Permit No. 82/2017). Our heartfelt thanks to the Principal Chief Conservator of Forests and Chief Wildlife Warden, Tamil Nadu, Field Directors, Chief Conservator of Forests, and District Forest Officers of the Sathyamangalam and
Mudumalai Tiger Reserves for granting permission to survey the area as well as timely help during fieldwork. Our deepest gratitude to the Dean and the Director at the Wildlife Institute of India, Dehradun, for their support and encouragement.

\section{Literature Cited}

Ali, S. and S.D. Ripley. 2001. Handbook of the Birds of India and Pakistan. Volume 5. Larks to the Grey Hypocolius. Oxford University Press, New Delhi, India.

Asokan, S., A.M.S. Ali, and R. Manikannan. 2009. Preliminary investigations on diet and breeding biology of the Indian Roller Coracias benghalensis in a portion of Cauvery Delta, Tamil Nadu, India. World Journal of Zoology 4 : 263-269.

Biddulph, C.H. 1937. The Southern Indian Roller or Blue Jay [Coracias benghalensis indica (Linn.)] killing a small snake. Journal of the Bombay Natural History Society 39: 865 .

BirdLife International. 2016. Coracias benghalensis. The IUCN Red List of Threatened Species 2016: e.T22725914A94905872. https://dx.doi.org/10.2305/IUCN. UK.2016-3.RLTS.T22725914A94905872.en.

Sivakumaran, N. and K. Thiyagesan. 2003. Population, diurnal activity patterns and feeding ecology of the Indian Roller Coracias benghalensis (Linnaeus, 1758). Zoos' Print Journal 18: 1091-1095.

Soud, R., M. Kripaljyoti, and G. Abhik. 2010. Predation by White-throated Kingfisher Halcyon smyrnensis on Common wolf Snake Lycodon aulicus (Linnaeus). NeBIO 1: 53-54.

Vyas, R. and B.H. Patel. 1995. Length record of the common wolf snake (Lycodon aulicus) from Bharuch, Gujarat. Journal of the Bombay Natural History Society 92: 271 .

Whitaker, R. and A. Captain. 2004. Snakes of India. The Field Guide. Draco Books, Chennai, India. 